\title{
O novo status do saber na era tecnológica e os desafios para a educação segundo Hans Jonas
}

\author{
The new status of knowledge in the technological era and the challenges \\ for education according to Hans Jonas
}
El nuevo status del conocimiento en la era de la tecnología y los desafíos para la educación de acuerdo con Hans Jonas

JELSON ROBERTO DE OLIVEIRA* \begin{abstract}
$\diamond$
\section{RESUMO}

O objetivo do presente artigo é abordar a mudança no estatuto do saber a partir da era moderna e suas repercussões sobre a educação no século XXI, tendo como referência a filosofia de Hans Jonas. Para tanto, analisa-se como o conhecimento perdeu seu valor contemplativo, ontológica e politicamente falando, para assumir uma perspectiva de exploração do mundo, chegando a apresentar-se ele mesmo como uma mercadoria, na forma da informação. Contrapõe-se, assim, o homo faber ao homo sapiens, com o prejuízo do segundo. À educação cabe enfrentar a tensão entre o fazer e o saber, recusando uma visão simplista da ideia de competências e assumindo uma posição crítica capaz de preparar o ser humano integralmente para assumir a sua responsabilidade diante dos novos poderes da tecnologia.
\end{abstract}

Palavras-chave: Educação. Conhecimento. Hans Jonas. Competências. Tecnologia.

\begin{abstract}
The purpose of this paper is to analyze the change in the status of knowledge in the modern era and its impact on education in the twenty-first century, with reference to the philosophy of Hans Jonas. We will analyze how knowledge lost its contemplative value, ontological and politically speaking, to assume a perspective of the world's exploration, presenting itself as a commodity in the form of information. Opposes, therefore, the homo faber to homo sapiens, with the loss of the second. To education fits face the tension between doing and knowing, refusing a simplistic view of the simplistic idea of competencies and assuming a critical position able to prepare the human being to assume his responsibility in the face of the new powers of technology.

Keywords: Education. Knowledge. Hans Jonas. Competencies. Technology.

\section{RESUMEN}

El propósito de este trabajo es analizar el cambio en el estado de conocimiento a partir de la era moderna y su impacto en la educación en el siglo XXI, con referencia a la filosofía de Hans Jonas. Vamos a analizar cómo el conocimiento pierde su valor contemplativo, ontológica y políticamente hablando, para asumir una concepción de exploración del mundo, llegando a presentarse a sí mismo como una mercancía en la forma de información. Se opone, por lo tanto, el homo faber al homo sapiens, con la pérdida del segundo. A la educación resulta necessario enfrentar a la tensión entre el hacer y el saber, rechazando una visión simplista de la idea de las habilidades y asumindo una posición crítica capaz de preparar al ser humano para asumir plenamente su responsabilidad ante los nuevos poderes de la tecnología. Palabras clave: Educación. Conocimiento. Hans Jonas. Habilidades. Tecnología.
\end{abstract}

\footnotetext{
* Doutor em Filosofia, Professor do Programa de pós-graduação em Filosofia da Pontifícia Universidade Católica do Paraná. E-mail: <jelsono@yahoo. com. $b r>$. O presente artigo é parte de pesquisa de pós-doutorado realizado na Universidade de Exeter, Reino Unido, com apoio da CAPES (processo BEX 6115/15-2)
} 


\section{INTRODUÇÃO}

"A educação tem um fim determinado como conteúdo: a autonomia do indivíduo, que abrange essencialmente a capacidade de responsabilizar-se." (Hans Jonas)

"Todos os seres humanos têm, por natureza, desejo de conhecer." Com essa famosa frase, Aristóteles inicia a sua Metafisica, tematizando a tendência ao conhecimento como parte central da essência humana. O que talvez soe estranho aos ouvidos contemporâneos seja a continuação da asserção, na qual o filósofo destaca como "prova" dessa disposição o "prazer das sensações" que, "fora até da sua utilidade, nos agradam por si mesmas" e, "mais do que todas as outras, os visuais" (1984, p. 11). Para Aristóteles, a visão é, entre os sentidos, o que mais faz conhecer as coisas. O pano de fundo dessa convicção é a concepção de que o ser humano, como ser racional, realiza-se plenamente através da contemplação da verdade, ou seja, da teoria. Sem negar a importância das sensações e da experiência, o estagirita destaca a capacidade humana de raciocinar, contrapondo a filosofia como ciência das causas à mera empeiría e téchne, ou seja, afirmando que "há mais saber na arte do que na experiência", já que a pergunta sobre o porquê das coisas é superior àquela que se ateve ao quê e ao como.

O modelo de educação derivado desses princípios prioriza a discussão, a reação e o debate com os estudantes, uma metodologia utilizada pelo próprio Aristóteles e que deveria contribuir para que os espíritos pudessem alcançar a nobreza de caráter e aproximar-se da perfeição e da felicidade, por meio de uma investigação comum que garantiria aos discípulos a capacidade de crítica do conhecimento apresentado pelo mestre. À educação caberia, portanto, primordialmente, um trabalho de reflexão, um esforço crítico capaz de transformar os conteúdos recebidos e se deixar transformar por eles. Jean Lombard (1994, p. 11), lembra que o modelo aristotélico está baseado em uma intersecção entre ensino e pesquisa, o que pode ser verificado pela própria redação de textos como Meteoro(?)logia, Das partes dos animais e mesmo o De anima, que teriam sido redigidos ou alterados pelo filósofo a partir dos debates com os estudantes. Educar, assim, é uma prática capaz de conduzir o indivíduo à condição de cidadão: como o propósito do ato educativo é a felicidade, e esta só pode ser pensada a partir da vida na pólis, ou seja, como preocupação política, então, na tentativa de realizar plenamente a natureza humana, a paideia estaria intimamente ligada à politeia, como sugeriu Weiss (2007). Nesse contexto, educar é despertar as virtudes não apenas como algo que se conhece, mas como algo que se pratica e que se aprimora com a prática, mas que, sobretudo, capacita para que a prática seja avaliada eticamente por meio do conhecimento dos valores e das virtudes ${ }^{1}$.

Esse modo de compreensão da relação do ser humano com o saber pode, como se disse, causar estranhamento hoje em dia, pois se está marcado por uma concepção de conhecimento em que a pergunta sobre as causas ficou em segundo plano em relação à pergunta sobre os efeitos. Tida como ocioso assunto metafísico, a pergunta sobre as coisas primeiras e últimas foi substituída, a partir da ciência moderna, por uma tentativa de compreensão do funcionamento, fazendo com que o conhecimento assumisse uma perspectiva de utilidade prática de domínio sobre a realidade. Estariam contrapostos, assim, o velho Organon aristotélico e o Novum organon baconiano, publicado em 1620, do qual derivaram as normas da obtenção do conhecimento, boa parte delas em vigor ainda hoje. Bacon acusa o modelo platônico e aristotélico de ser apenas retórico-literário, baseado em verdades prontas que poderiam ser acessadas pela contemplação racional. No seu lugar, propõe um conhecimento que possibilite a intervenção na natureza, a transformação pela ação, a experimentação e o domínio dos processos. Em oposição ao discurso formal qualitativo, Galileu, um dos ícones desse modelo moderno, prioriza o testemunho dos sentidos e, principalmente, conta com o auxílio da técnica na explicação das qualidades dos fenômenos e na descrição quantitativa do mundo. Condenando a autoridade dos antigos, principalmente a de Aristóteles, Galileu escreve no seu $O$ ensaiador:

Parece-me também perceber em Sarsi sólida crença que, para filosofar, seja necessário apoiar-se nas opiniões de algum célebre autor, de tal forma que o nosso raciocínio, quando não concordasse com as demonstrações de outro, tivesse que permanecer estéril e infecundo. Talvez considere a filosofia como um livro e fantasia de um homem, como a Ilíada e Orlando Furioso, livros em que a coisa menos importante é a verdade daquilo que apresentam por (?) escrito. Sr. Sarsi, a coisa não é assim. A filosofia encontra-se escrita neste grande livro que continuamente se abre perante nossos olhos (isto é, o universo), que não se pode compreender antes de entender a língua e conhecer os caracteres com os quais está escrito. Ele está escrito em língua matemática, os caracteres são triângulos, circunferências e outras figuras geométricas, sem cujos meios é impossível entender humanamente as palavras; sem eles nós vagamos perdidos dentro de um obscuro labirinto (GALILEI, 1983, p. 130).

\footnotetext{
Essa interpretação evidencia como a avaliação de Bacon e de outros pensadores modernos quanto ao conhecimento em Aristóteles não é completa: ao insistirem no seu caráter contemplativo do ponto de vista epistemológico, eles acabam por esquecer que ela tem um caráter éticopolítico bastante prático.
} 
Passagem que evidencia a mudança importante proposta pela modernidade quanto à noção de conhecimento: desvencilhar-se das autoridades do passado e aprender a ler o livro da natureza, decifrar os seus caracteres e alfabetizar-se em seus algoritmos. A verdadeira filosofia, assim, convertida em ciência, atira-se à tarefa que transformou o conhecimento em um serviço técnico de intervenção no mundo. $\mathrm{O}$ desenvolvimento dessa estratégia atravessou quase cinco séculos e se desdobrou em uma nova mudança a partir de meados do século XX, quando as chamadas sociedades industriais desenvolvidas viveram uma revolução que transformou o antigo modo de fazer ciência, basicamente porque reduziu o conhecimento a mera informação.

Lyotard escreveu, em 1979, um marcante livro sobre A condição pós-moderna, no qual detectou uma mudança na posição do saber nas sociedades pós-industriais. Já no primeiro parágrafo de sua obra, ele anuncia que sua "hipótese de trabalho é a de que o saber muda de estatuto ao mesmo tempo que as sociedades entram na idade dita pós-industrial e as culturas na idade dita pósmoderna" (1988, p. 3). O diagnóstico do filósofo francês dava conta de uma mudança no estatuto da ciência e, consequentemente, da própria universidade como lugar de produção do conhecimento. Por isso, o livro é uma espécie de inventário das mudanças provocadas pelo avanço das tecnologias sobre os saberes científicos, filosóficos e artísticos: se o século XIX é marcado pela crise das verdades, o esforço do século seguinte foi o de enquadrar o saber em novas categorias, entre as quais destacam-se as ideias de performance, eficácia e... competência. E estas não seriam mais do que manobras legitimadoras do modelo produtivo em vigor e que teriam transformado a ciência em um mero processo de busca, organização e armazenamento de informação, ela mesma transformada em um produto entre outros. Assim, reduzido a informação e mercantilizado, o conhecimento passa a ser medido em quantidades, sob o anseio de ser transferido de um lugar a outro ou, mais especificamente, de uma mente a uma máquina, e, daí, de uma máquina a outra. Esse modelo tornou o conhecimento alguma coisa compatível com a máquina, algo que, no limite, estaria carregado de um valor de troca, um valor utilitarista que cresce sob os umbrais da funcionalidade e da vantagem econômica para os indivíduos que o detêm (segundo o modelo da posse) ou que detêm os seus equipamentos (no caso, as máquinas). Enfraquecido em suas versões éticas, sociais, humanas e humanísticas, o conhecimento é comercializado em função dos seus benefícios práticos e de seus ganhos financeiros imediatos.

Esse processo trouxe inúmeras consequências para a educação, o locus central onde, tradicionalmente, o conhecimento tem sido gerado e promovido. As instituições de ensino precisaram, a partir de então, lidar com um conhecimento "deslegitimado" e acabaram, em muitos casos, rendendo-se à nova tarefa de educar para o mercado do saber ou, melhor dizendo, para o mercado que transformou o saber em uma mercadoria. O pensamento ético do filósofo alemão Hans Jonas pode contribuir tanto para uma avaliação diagnóstica dessa mudança no estatuto do saber quanto para uma análise de suas consequências éticas, apontadas por ele na missão educativa de responsabilidade dos sujeitos diante do uso do novo saber/poder tecnológico.

\section{UMA MUDANÇA NO STATUS DO SABER}

Ao se perguntar por que a técnica se tornou um objeto obrigatório da filosofia e da ética, Hans Jonas recua até os inícios da modernidade, onde ele identifica a instauração de um movimento de mudança no status do saber, algo que, no limite, seria para ele a característica central da modernidade. Assim, Jonas não só concordaria com o diagnóstico de Lyotard, por exemplo, como o interpretaria como desdobramento de movimentos anteriores nos quais se fundamentou o avanço da chamada civilização tecnológica, marcada pela "dinâmica formal" que transformou a técnica em uma "empresa coletiva" em vista da produção de um "conteúdo substancial", ou seja, de "coisas que aporta para o uso humano, o patrimônio e os poderes que confere, os novos objetivos que abre ou dita e as próprias novas formas de atuação e conduta humanas" que fomenta $\left(\mathrm{TME}^{2}, 25\right)$. Em outras palavras, segundo Jonas, a era moderna é marcada por um processo de transformação do conhecimento em uma ferramenta útil para a produção de bens - de domínio, de consumo e de posse. A mudança no modo como se entende o que é conhecimento seria a premissa ontológica e gnosiológica da possiblidade do avanço tecnológico, que teve como consequência a redução do papel da educação a um repasse utilitarista de informações e conteúdos úteis para o negócio da vida. E também para as sempre novas demandas que se abrem pela exigência de inovação, eficácia e competência e para a criação de novas necessidades capazes de alimentar o avanço desenfreado do consumo dos novos produtos.

Para Jonas, por isso, a mudança no estatuto do saber ocorreu porque a "velha e honorável separação entre 'teoria' e 'prática' desapareceu" e a "sede de conhecimento puro, o entrelaçamento entre conhecimento

\footnotetext{
${ }^{2}$ Usam-se as siglas convencionais para a citação das obras de Hans Jonas: TME (Técnica, medicina e ética); PR ( $O$ princípio responsabilidade); e SDD (para o ensaio $O$ século dezessete e depois: o significado da revolução científica e tecnológica). Seguindo a sigla referente ao título da obra, está o número da página. Para os demais autores, segue-se o sistema autor-data.
} 
nas alturas e ação na planície da vida, tornou-se insolúvel e a aristocrática autossuficiência da busca pela verdade por si mesma desapareceu" (TME, 39). Nesse sentido, o campo teórico teria sido socializado na forma das várias utilidades concretas do cotidiano. A fórmula de Jonas sintetiza como esse processo levou a uma importante mudança no campo do conhecimento: "Trocou-se a nobreza pela utilidade" (TME, 39). A antiga aristocracia teórica da verdade que estava centrada na realização plena do ser humano, assim, foi substituída por uma "socialização" (TME, 40) dos saberes em benefício do fazer, ou seja, em direção à realização exclusiva dos potenciais técnicos do homem. Isso porque a civilização tecnológica manteria uma "visão teórica subjacente" (TME, 35), segundo a qual, em sentido ontológico, as coisas do mundo se abrem sempre em novas camadas a serem conhecidas; e, em sentido epistemológico, porque o conhecimento, traduzido em "descobrimento e invenção", passou a ser uma ação incessante, validada pelos aparatos tecnológicos que substituem aquela tendência natural apontada por Aristóteles por um conhecimento prático que se desenvolveu a partir da "inter-relação entre ciência e técnica". Algo que é, segundo Jonas, "a característica do progresso moderno" (TME, 36). Para o autor, é "no movimento do conhecimento onde primeiro e continuamente aparece a novidade mais importante", ou seja, é no âmbito do pensar que esse processo se funda: de um lado, tem-se uma natureza que se oferece sempre de novo em sua "infinitude virtual"; de outro, um conhecimento que, "ao invés de reduzir a margem do que resta para ser descoberto", acaba por surpreender-se "com dimensão após dimensão de novas profundidades" a serem conhecidas e/ou alteradas. O conhecimento tornou-se uma "investigação sem fim" em busca da inovação ou da novidade, ela mesma convertida em epíteto recomendatório dos novos tempos, os tempos modernos:

A grande virada é marcada pelo uso sempre mais frequente do epíteto laudatório "novo" para uma variedade sempre maior de iniciativas humanas - na arte, na ação e no pensamento. Essa moda linguística seria grave ou fútil dependendo do caso, nos diz uma série de coisas. A elevação do termo a atributo laudatório denuncia certo cansaço, até mesmo certa impaciência com as formas de pensar e de viver até então dominantes. O respeito pela sabedoria do passado é substituído pela suspeita de um erro inveterado e pela desconfiança de uma autoridade inerte. Isso vem acompanhado de um novo estado de autoconfiança, de uma firme convicção de que nós modernos estamos mais bem equipados do que os antigos - e certamente melhor do que nossos antecessores imediatos para descobrir a verdade e melhorar muitas coisas (SDD, 81).
Tal progresso científico se deu simultaneamente por meio do progresso tecnológico que o sustentou, pois o avanço nos equipamentos de acesso aos recônditos da natureza desenvolveu-se como um "subproduto externo" do novo status do conhecimento: "Para alcançar seus próprios objetivos teóricos, a ciência necessitava de uma tecnologia cada vez mais refinada e fisicamente forte como ferramenta que se produz a si mesma" (TME, 38). Em outras palavras, porque o conhecimento agora é compreendido como exploração infinita do mundo, então foi preciso desenvolver ferramentas que sustentassem essa tarefa. A ciência, assim, transformou, com o serviço da técnica, a natureza em um laboratório de grande escala, em "uma incubadora para novas perguntas", em um círculo indeterminado e infinito, nunca passível de qualquer saturação. Para Jonas, portanto, o conhecimento foi reduzido a uma versão utilitarista e intervencionista amparada tecnologicamente. Isso significa que os antigos reinos teórico e prático se diluíram em uma única estratégia, levada a cabo como "mútua relação de feedback" entre ciência e técnica, em um recíproco movimento de impulso e necessidade, segundo um vínculo que Jonas caracteriza como "funcional" e que acaba por fazer com que a ciência se transforme em um "agente de infatigabilidade" para a tecnologia (TME, 38).

O problema é que, tendo perdido sua raiz reflexiva e seu potencial de realização da essência humana em sentido pleno, "a aspiração ao conhecimento" se transformou em uma atividade meramente operacional, guiada por um avanço ininterrupto adiante, marcado por um afã por "novos passos em todas as direções possíveis", diluindo os próprios objetivos e inventando sempre novas necessidades. Conhecimento que se transforma, assim, em um impulso cego, amparado em uma "impressionante história de êxitos" (TME, 21) e em uma confusão entre meios e fins, já que não há mais linearidade dos processos, mas circularidade (objetivos podem ser satisfeitos com novas técnicas e vice-versa). Novas necessidades e objetivos não solicitados guiam a atividade do homo faber, que passa a ver nessa tarefa uma necessidade vital, principalmente quando associada à atual "dieta socioeconômica". O conhecimento se coloca a serviço do "progresso", um impulso incerto e sem direção, que se torna um valor em si mesmo, "um adorno ideológico da moderna tecnologia" (TME, 31). Atrelado a essas malhas da atividade produtiva da inovação constante, o conhecimento se transforma, também ele, em um produto, na medida em que está embutido nas próprias ferramentas que inventa.

Segundo Jonas, o prejuízo central desse modelo seria não necessariamente a socialização dos saberes, mas a ilusão dessa pretensa democratização do conhecimento e, principalmente, a sua redução em termos epistemológicos 
e culturais. Transformado em mera ferramenta de serviço diante do mundo, o conhecimento tornou-se "em si mesmo culturalmente débil", e o risco parece ainda mais grave quando associado a um fazer técnico que se desligou da reflexão e, com isso, perdeu a capacidade de meditação ontológica (sobre o ser das coisas que altera e sobre a imagem das coisas que pretende inventar) e ética (sobre o dever contido no uso dos novos poderes). Em outras palavras, sem aquela antiga capacidade reflexiva e reduzido aos expedientes utilitários e funcionais da tecnologia, o conhecimento se transformou em um perigo para o próprio homem. O processo, para Jonas, apresentase como uma crise cultural, porque o conhecimento estaria "em risco de abrandar-se ou de converter-se em rígida ortodoxia - esse eros teórico já não vive só do delicado apetite pela verdade, senão que é estimulado por seu rebento mais robusto, a técnica" (TME, 38). O "eros teórico", ou seja, aquele "desejo de conhecer", apontado por Aristóteles, foi reduzido a uma ortodoxia na medida em que implantou-se como um imperativo vocacional de cada indivíduo e da civilização como um todo, sob os riscos e perigos de uma tecnociência livre de valores e de responsabilidade. O homo faber, porque suplantou o homo sapiens, acaba por conduzir a civilização atual para um conjunto de perigos nunca antes imaginado e para o qual o atual estágio do conhecimento deixou-a totalmente despreparada para a necessária avaliação da consequência dos usos dos novos poderes.

\section{UMA EDUCAÇÃO PARA O FAZER}

O modelo educacional foi amplamente impactado por esse novo estatuto do conhecimento, fazendo com que, muitas vezes, as instituições educativas reduzissem os seus experientes a uma formação tecnicista do homo faber na forma de profissionais qualificados para o serviço técnico. Essa redução do conhecimento à sua funcionalidade foi tematizada por Michael Young, para quem "o papel central do conhecimento na educação tem, sem dúvida, declinado no decorrer dos anos" (2016, p. 20), tanto por motivos políticos quanto por causas internas às próprias comunidades educativas. O exemplo da Inglaterra, segundo ele, seria paradigmático, na medida em que os atores políticos teriam transformado as políticas de educação em mera política econômica, tendo como resultado a substituição do conhecimento pelo discurso da habilidade: trata-se de postergar a reflexão em nome da urgência dos benefícios econômicos da ciência, de incentivar a perspectiva produtiva e funcional do regime estruturado em torno da dependência do consumo e de minimizar ou até mesmo anular qualquer tipo de questionamento de cunho ético ou político que possa representar um empecilho para o avanço da economia de livre-mercado.
Essa crise vem sendo alargada pela dúvida cética sobre o valor do conhecimento, algo que marca a sociedade contemporânea e que foi primeiramente definida pelo filósofo alemão Friedrich Nietzsche como uma tendência niilista da cultura que acatou a dúvida sobre a verdade única como um dos seus principais aspectos. A chamada pósmodernidade, assim, cresceu sob os auspícios da escola da suspeita inaugurada pelos pensadores do fin du siècle, marcado pelo ceticismo e pela décadence que colocaram em xeque qualquer conhecimento objetivo. Algo que, segundo Young, teria afetado fortemente os debates e os estudos sobre educação, resultando em uma perspectiva cada vez mais "situada" dos saberes e em um crescente ceticismo em relação às próprias estratégias educativas, potencializado pelos pretensos fracassos quanto aos interesses e às motivações dos discentes e dos docentes. Na prática, esse clima acabou tendo consequências para o currículo na medida em que: "Se todo conhecimento está situado em um contexto, isso leva a um relativismo que rejeita a suposição de haver um conhecimento 'melhor' em qualquer área, que poderia ou deveria embasar o currículo escolar. Como consequência, o currículo se torna aberto a toda uma variedade de finalidades outras que não sejam a aquisição de conhecimento" (YOUNG, 2016, p. 21). Ainda que a solução proposta por Young (que ele chama de "conhecimento poderoso") seja questionável, principalmente pelo seu acento na especialização dos saberes (justamente um dos pontos centrais da ideia de progresso e "motor de divisões", algo que foi amplamente criticado pelos autores da teoria da complexidade, principalmente Edgar Morin), é importante notar que seu diagnóstico recolhe as consequências daquela mudança no estatuto do saber apontado por Jonas (e também por Lyotard).

Se essa desconfiança em relação à verdade for somada à redução do conhecimento aos serviços técnicos de exploração do mundo, os currículos e os objetos da educação acabam por se render à lógica da mera acumulação de informação e conteúdo cuja utilidade é direcionada tanto pelos objetivos econômicos quanto pelos novos horizontes ideológicos e utópicos representados pela própria tecnologia. De um conjunto de saberes, o conhecimento se transforma, aos poucos, em um arquipélago fragmentário de fazeres, cujo acento tecnológico transforma em poderes. À educação cabe apenas o gerenciamento desses fazeres, sua transmissão na forma de habilidades capazes de contribuir para que o profissional (e não o cidadão) saiba utilizá-los em benefício da retroalimentação do progresso técnico, agora tido como meta da vida humana, algo que se torna, afinal, mais convincente na medida em que suas promessas se concretizam em êxitos. O conhecimento, assim, vai perdendo aos poucos tanto o seu potencial realizador da 
natureza humana, herdado do mundo antigo, quanto o seu potencial emancipatório, herdado do iluminismo, gerando uma insistente ênfase na relatividade do saber, ou seja, na sua redução às circunstâncias locais e à realidade de seus sujeitos. Tal ênfase conduz, inclusive, à insistência no valor da aprendizagem, absolutamente legítima quando contraposta à centralidade do ensino, compreendido como as estratégias didáticas de transmissão de conhecimento, mas que pode acabar por ter um prejuízo quando comparada ao conhecimento em si mesmo, porque abre caminho para o uso funcional do saber. Finalmente, o estudante precisa aprender para "se dar bem na vida" e contribuir para o progresso da sua comunidade, não necessariamente para se realizar enquanto ser humano. O perigo é que o destaque dado à aprendizagem do estudante acabe deslizando para uma hipertrofia da utilidade, na medida em que aqueles tipos de conhecimento considerados "inúteis" ou até mesmo "danosos" ao avanço cego do progresso tecnológico sejam colocados em segundo plano ou até mesmo excluídos dos currículos. É o que pode acontecer, por exemplo, com disciplinas da área social ou de humanas, quando não são capazes de demonstrar sua contribuição para o progresso desejado, fazendo com que os impactos dessas tendências sobre as humanidades seja bastante relevante, com a redução dos investimentos e escanteamento das disciplinas e dos cursos nos ambientes educacionais.

A difícil interrogação que nasce desse contexto pode ser formulada nos seguintes termos: a que conhecimento os alunos devem ter acesso na escola? A pergunta, no fim, está ligada às concepções de mundo mais íntimas, às ideias de felicidade e bem-estar que se tem, aos valores e aos pressupostos das constituições pessoais e culturais. Afinal, o que se precisa conhecer para atingir esses ideais ou para se enfrentar os imensos desafios da inclusão social, da luta contra a desigualdade, da preservação ambiental e de todas as outras urgências de nosso tempo? E como se pode garantir acesso igualitário ao conhecimento como direito? Quem teria esse direito? Levando em conta a prerrogativa da isonomia educativa, como garantir um mesmo conhecimento para todos? Young apresentou o problema em termos de distribuição do conhecimento ao qual poderia ser acrescentada a questão sobre o tipo de conhecimento, tendo em conta processos que priorizaram a formação de mão de obra das classes mais baixas para o mercado de trabalho. Com isso, a ênfase na aprendizagem, quando reduzida à utilidade do conhecimento orientado para as atividades práticas e em vista do enfrentamento de problemas sociais específicos, acaba por comprometer os aspectos de plenitude humana que está contido na ideia de conhecimento.

Como se sabe, a educação por competências está ligada a um forte acento na aprendizagem e, nesse sentido, ela carrega alguns perigos que precisam ser evitados. Primeiro, o fato de que o acento na necessidade de resposta imediata, utilitária e funcional do conhecimento e sua aplicação a realidades concretas pode reduzir o processo educativo a índices quantitativos segundo o modelo exclusivo de uma educação por resultados, no qual indicadores como aprovação em exames e empregabilidade ganham relevância, em detrimento de elementos epistemológicos, éticos ou político-cidadãos. Outro perigo diz respeito ao problema da "autoridade" do conhecimento e do próprio professor. No primeiro caso, a imposição do conhecimento "situado", que dá prioridade ao tipo de saber derivado das experiências concretas de um indivíduo em sua localidade e em seu tempo, pode contribuir para um esvaziamento dos conhecimentos "independentes do contexto" (YOUNG, 2016, p. 10), justamente aqueles que fazem parte das abstrações que sistematizam o concreto e lhe dão caráter generalizado, o que, desde Platão, faz parte do ato de conhecer. Tal posição se apoia, aliás, na justa defesa do direito à diferença e da multiculturalidade que deve animar o ato educativo, sem dúvida, mas que pode trazer graves prejuízos se não estiver acompanhada de uma reflexão a respeito dos conhecimentos que são de todos e para todos. $\mathrm{O}$ exagero do contexto, nesse caso, poderia levar à perda do potencial libertador do conhecimento, agora atrelado à prisão da experiência situada e às circunstâncias de cada sujeito. Este, o campo do construtivismo exacerbado. Se a abstração do conhecimento é um mal a ser seriamente combatido, o seu encerramento no âmbito privado das circunstâncias e das internalidades culturais é o outro lado de uma mesma moeda. Lutar contra a centralidade do poder e contra a tirania dos currículos centrais e dos seus arautos não significa relativizar toda ideia de autoridade, porque é preciso fazer uma diferença entre "poder sobre" e "poder com". Foucault, por exemplo, na esteira de Nietzsche, demonstrou que o poder nem sempre é central e que sua estrutura é microfísica, ou seja, ocorre como uma rede, compartilhada em um jogo de frequentes mudanças. Professores experientes e "qualificados" continuam sendo uma demanda indispensável de todo processo educativo, não para exercerem um poder sobre os estudantes, mas para mediarem um poder com eles e, assim, educarem para o uso do poder, para a exposição de todos a esse poder, para o exercício de sua distribuição, para o proveito de seus benefícios e para a minimização de seus riscos. O professor não pode reduzir a sua atividade simplesmente ao conhecimento de estratégias didáticas e metodologias que motivem os estudantes a fazerem por si mesmos, um processo que pode levar para um lugar de conforto em relação ao que ele mesmo deveria saber e também transmitir. E o excesso discursivo é um erro; mas a hipertrofia da atividade também pode ser, na 
medida em que ela desconecta ensino e pesquisa, esvazia o ensino de seu conteúdo e o reduz à condução de técnicas que coloquem os estudantes em ação, aprendendo por si mesmos ou com seus pares, prescindindo da dupla autoridade, a do conhecimento e a do professor. Mais uma vez, isso não significa que as experiências particulares não possam transformar o próprio conhecimento (que, afinal, permanece como um problema) ou que os estudantes não possam questionar a autoridade central do professor. Obviamente, isso está em jogo e deve assim permanecer. Trata-se, contudo, de evocar os riscos de um exagero oposto àquele da centralidade no ensino.

Em outras palavras, a justa defesa do multiculturalismo não pode prescindir da ideia de que todos os conhecimentos devem ser para todos. Para Young, esse problema pode ter como pressuposto uma visão equivocada da autoridade, em um tempo no qual as autoridades parentais (pais, professores, padres, pastores, patrões e políticos em geral) estão em descrédito. Tudo se passa como se "a autoridade fosse algo incômodo e não democrático" (2016, p. 10) e como se ela não fosse suficiente para desenvolver a relação dos estudantes com o conhecimento, uma autoridade que, no limite, teria perdido terreno para outras ferramentas, como as sedutoras tecnologias de comunicação. Em outras palavras, respeitar o professor não significa mantêlo no centro do processo educativo todo o tempo, mas também não é esvaziar completamente a sua autoridade. Sem autoritarismo, o professor deve favorecer um poder compartilhado e equitativo que se dá na relação entre ele mesmo, os estudantes e o conhecimento, de forma que todos saiam transformados dessa experiência. Por isso as instituições de ensino não podem senão se reconhecerem como "comunidades educativas", uma rede interconectada de saberes complementares e relativos (no sentido de serem relacionais). Só assim haverá, de fato, emancipação. Do contrário, estarão sendo formados operários para a técnica e não seres humanos.

Isso significa que a educação não pode, de maneira nenhuma, render-se à utilidade tecnicista do conhecimento que fora denunciada por Jonas. Uma das premissas da educação que Young defende é de que o "conhecimento vale a pena por si só" $(2016$, p. 14) e, com isso, ele retoma a visão aristotélica que se contrapõe à funcionalidade do saber. É preciso fugir da abstração ociosa, mas também é preciso aprender a tomar distância do cotidiano: esse gosto por lonjuras é, na verdade, a porta para se chegar perto das próprias circunstâncias; é dele que deriva o empenho de transformação da realidade: transformando o conhecimento pela tensão entre o próximo e o distante. E, transformados por ele, os indivíduos estão aptos para transformar o mundo que os cerca.

\section{A TENSÃO DO CONHECIMENTO: ENTRE O FAZER E O SABER}

Ainda que Jonas não tenha escrito nenhum texto a respeito, os desdobramentos dessa problemática no campo da educação são evidentes e têm despertado o interesse de muitos pesquisadores, principalmente da chamada educação ambiental. Em uma passagem da sua obra de 1979, O princípio responsabilidade, o filósofo define a educação nos seguintes termos:

\begin{abstract}
A educação tem, portanto, um fim determinado como conteúdo: a autonomia do indivíduo, que abrange essencialmente a capacidade de responsabilizar-se; ao alcançá-la (ou supor-se que foi alcançada), ela termina no tempo. O término ocorre de acordo com sua própria lei, e não de acordo com a concordância do educador nem sequer na medida de seu êxito -, pois a natureza concede apenas uma só vez um determinado lapso de tempo, no qual a educação precisa realizar sua tarefa. Depois disso, o objeto de responsabilidades anteriores se torna, ele mesmo, um sujeito de responsabilidades (PR, 189).
\end{abstract}

Malgrado a passagem ter um motivo específico (o debate em torno do papel do pai e do político) e uma visão ampliada da educação (não apenas resumida à instituição escolar), ela fornece uma definição bastante rica. A tarefa da educação reúne autonomia e responsabilidade e está diretamente conectada com o horizonte do futuro, ou seja, com a exigência de que o crescimento pessoal e os interesses privados de um indivíduo estejam acompanhados de sua capacidade de pensar eticamente o seu compromisso com a humanidade presente e futura. Jonas une, portanto, a historicidade e a natureza em um único princípio capaz de orientar a tarefa educativa. A consequência dessa noção exige uma revisão no conceito de conhecimento e na sua função: para Jonas, a nova ética deve ser capaz de reunir os saberes científicos em torno de uma projeção dos "efeitos distantes da ação técnica" (PR, 70), algo que ele assume como "o primeiro novo valor a ser exercitado hoje para o mundo de amanhã" (TME, 42), ou seja, a capacidade de previsão. No horizonte das preocupações filosóficas de Jonas, assim, a educação deve se desvencilhar de sua tarefa autocentrada de incentivo à tecnologia e dedicar-se à articulação de saberes em torno da formação de uma "ciência da previsão hipotética" (PR, 70) que faça do conhecimento um saber que "se origina daquilo contra o que devemos nos proteger" (PR, 71). À educação cabe, assim, o papel de capacitar os sujeitos para o "reconhecimento do malum" (PR, 71) de suas próprias ações, consultando o temor antes do que o desejo, fomentando o "conhecimento do possível" na forma de uma "heurística" capaz de 
despertar o sentimento de responsabilidade e evitar a aposta arriscada que vem sendo levada a cabo pela tecnologia ideologicamente associada ao progresso e financiada pelas grandes corporações. Jonas questiona o que ele chama de "crença supersticiosa na onipotência da ciência" (PR, 205). Para ele, a educação não deve ser um esforço para fazer o homem se adaptar ao novo cenário tecnocientífico, mas um ato de questionamento sobre a sua lógica interna. Às instituições educativas, assim, cabe assumir a responsabilidade sobre um objeto (o próprio ser humano em formação, os estudantes) para torná-lo, ele mesmo, um sujeito responsável diante do conhecimento agora transformado em poder.

Em uma importante passagem do primeiro capítulo de sua obra Técnica, medicina e ética: sobre a prática do princípio responsabilidade, de 1985, Hans Jonas aponta, entre os aspectos filosóficos da técnica moderna, a sua rápida absorção e difusão na comunidade tecnológica, algo que seria explicado por aquilo que ele chama de "pressão da concorrência". Para o autor, "a difusão tecnológica se produz (...) tanto no plano do conhecimento como no da apropriação prática: o primeiro (junto com sua velocidade) vem garantido pela intercomunicação universal, por sua vez uma conquista do complexo tecnológico; o segundo, forçado pela pressão da concorrência" (TME, 30). Ou seja, de um lado o conhecimento se difunde com o apoio das novas tecnologias; de outro, ele é assumido como urgência por indivíduos que querem permanecer profissionalmente competitivos. Um pouco mais adiante, Jonas esclarece o seu conceito: a pressão da concorrência ocorreria "pelo benefício, mas também pelo poder, a segurança, o prestígio etc. - como um perpetuum movens da universal apropriação das melhores técnicas" (TME, 32). Ou seja, no mundo do mercado, vale mais quem detém as melhores tecnologias (na forma de processos e dispositivos), quem é capaz de implementar modelos de inovação e empreendedorismo e de fomentar a novidade e o progresso. O "princípio comum" de "manter a cabeça acima d'água" torna-se, assim, uma lei geral que passa a orientar a atividade educativa. Sendo mais competente quem fosse capaz de sobrepor-se aos demais.

O conceito jonasiano de "pressão da concorrência" leva à noção de competências, que adentrou na educação brasileira de forma bastante conturbada, a partir dos desdobramentos da Lei de Diretrizes e Bases da Educação, de 1996, e dos Parâmetros Curriculares Nacionais (PCN, de 1999 e $\mathrm{PCN}+$ de 2002), e em certa medida repercutida pelas Orientações Curriculares para o Ensino Médio, de 2006. Entre seus teóricos, destaca-se o do francês Philippe Perrenoud, que teve vários de seus trabalhos traduzidos para o português. Como mostra Ricardo (2010), a noção de competências carrega o perigo de orientar unicamente a educação ao serviço da indústria e dos serviços produtivos em geral, daí o seu enfoque na ideia de uma junção entre o saber (que não mais bastaria em si mesmo) e o saber-fazer, em benefício de uma maior produtividade profissional, já que este deveria colocar o conhecimento à disposição do empregador e dos seus anseios, na forma de habilidades produtivas. Mais uma vez, chega-se ao campo dos riscos do exagero. O conhecimento pode se transformar, assim, em um dispositivo a serviço do lucro e passa a guiar os contratos de trabalho pela lógica de sua funcionalidade, fazendo com que a educação esteja empenhada em formar esses operários para o fazer e não necessariamente para o pensar. Nesse fazer, contudo, não estão apenas inseridas as habilidades para manusear as máquinas. $\mathrm{O}$ novo modelo produtivo globalizado passa a incluir "aspectos da personalidade dos trabalhadores, como responsabilidade, iniciativa, comunicação, empreendedorismo", que são "enfatizados em detrimento de qualificações técnicas, pois sobrevivem à automatização e parecem responder melhor às crises" (RICARDO, 2010, p. 608). Ou seja, as habilidades, por si mesmas, não são mais suficientes.

Retomando o problema do status do saber colocado por Hans Jonas, conforme apresentado acima, Ricardo afirma que os modelos educativos orientados por essa perspectiva "atribuem distintos status aos saberes e às práticas. Isso implica diferentes status na legitimação dos saberes que serão objetos dessas formações, bem como suas referências" (2010, p. 609). Essa mudança não tem sido evidenciada apenas nos chamados cursos técnico-profissionalizantes, mas nas próprias universidades. Trata-se,

obviamente, de uma visão empobrecida da noção de competências, facilmente combatida quando ligada a esse novo status do saber operacional. Uma visão que acaba por construir também subjetividades funcionais, já que a educação passa a reproduzir o ideal da empregabilidade e do sucesso profissional como elemento central de uma vida feliz. Sujeitados, os indivíduos são formados e treinados segundo aquele ideal do homo faber apontado por Jonas: um mero operário da técnica. Um prejuízo, sem dúvida, derivado daquele excesso de circunstâncias que leva a uma educação adaptativa, na qual os sujeitos são convocados mais a se ajustarem, de maneira individualista, ao novo ideal do que, necessariamente, à transformação de suas realidades por meio de ações coletivas e organizadas. O sujeito, agora, está entregue à sua capacidade de adaptação e de atualização e, não raro, é vitimado pelas incertezas abertas cotidianamente pelas incansáveis inovações tecnológicas em curso que o pressionam e exigem competência para enfrentar a concorrência.

Na medida em que as próprias Diretrizes Curriculares Nacionais insistem na necessidade de uma educação capaz de "assimilar as mudanças tecnológicas e adaptar-se às novas formas de organização do trabalho" (BRASIL, 
1999, p. 73), elas estão fomentando aquela tensão no que diz respeito ao status do conhecimento, que agora passa a ser avaliado pela instituição empresarial segundo seus próprios critérios de utilidade. Em outras palavras, a educação passa a ser avaliada pelo mercado quanto à sua eficácia e "se antes a escola era vista como uma promessa de emprego, agora passa a ser vista como um caminho para a empregabilidade, sob a responsabilidade de cada um" (RICARDO, 2010, p. 611). Em consequência, chega-se ao mesmo problema apontado por Young: o conhecimento passa a ser uma propriedade individual e sempre circunstancial, cujos interesses são sempre particulares. O risco é a transformação da escola em um espaço de negócio e de intercâmbio de experiências privadas, o que pode "conduzir a um subjetivismo e a um relativismo epistemológico" (RICARDO, 2010, p. 612), além de suas derivações éticas que minimizam o aporte dos valores e da responsabilidade, em nome de uma hipertrofia da produção e do avanço do progresso técnico desmedido.

Os trabalhos de Perrenoud, no geral, apresentam uma visão menos simplista da noção de competência, ainda que mantenham a insistência na "situação": "Uma capacidade de agir eficazmente em um determinado tipo de situação, apoiada em conhecimentos, mas sem limitar-se a eles" (PERRENOUD, 1999, p. 7). E também a veem como a reunião de "múltiplos recursos cognitivos: saberes, capacidades, microcompetências, informações, valores, atitudes, esquemas de percepção, de avaliação e de raciocínio" (PERRENOUD et al., 2002, p. 19). Essa noção combate a mera memorização de conteúdos e exige julgamento e capacidade de discernimento a respeito do que deve ser feito em determinada situação concreta, na qual a atitude reflexiva diante dos problemas reais é muito relevante. A estrutura de saberes anteriores é uma espécie de pano de fundo sobre o qual se desenvolve a capacidade de aplicação desses saberes e de sua renovação diante dos problemas. O conhecimento, nesse caso, deve estar sempre conectado com as práticas, em vista da utilização adequada dos instrumentos e dos recursos técnicos. Perrenoud acentua a importância dessa articulação e, com isso, compreende o papel da educação como a promotora da capacidade de mobilização dos saberes em vista desses conhecimentos, em papel ativo dos estudantes e não necessariamente perante a transferência de informações por parte dos docentes. Essa noção evoca valores e atitudes que ultrapassam o mero valor técnico, incluindo a capacidade de criar novas respostas e de transformar o conhecimento em contato com a realidade, e vice-versa. $\mathrm{O}$ acento óbvio no sujeito remete ao potencial intuitivo do aprendizado, capaz de analisar as situações concretas e de responder a elas da maneira mais adequada. Para Perrenoud, a escola não pode simplesmente repassar conhecimentos, porque é preciso capacitar o estudante para que ele mobilize os saberes e enfrente a complexidade do mundo ao seu entorno. Competência, nesse caso, aparece como uma espécie de alternativa ao modelo educativo centrado meramente na transmissão de conteúdos, ainda que deva ser pensada não como uma contraposição a estes últimos, já que eles estão integrados a ela como um de seus aspectos.

Essa descrição acentua a importância da relação entre conhecimento e situação, ou seja, da experiência concreta de aplicação e retroalimentação do conhecimento a partir das vivências próprias dos indivíduos. Isso é destacado também por Fourez ao debater a questão da transversalidade das competências, mas também dos saberes: para ele, é "em situações particulares que se desenvolvem as competências, métodos, modelos, noções ou conhecimentos" e só então elas podem ser transferidas para outras classes de situações (1999, p. 5). Estas, assim, mobilizam diferentes saberes e a necessidade de integrálos de diferentes formas. E esse é o "valor de uso" que as competências acrescentam ao conhecimento. Nesse sentido, mais grave do que o déficit de conhecimento dos estudantes, é a sua incompetência em utilizá-los. Dessa forma, destaca-se o potencial criativo do conhecimento, mobilizado por metodologias educativas que se realizem como esforço de integração de saberes capaz de vencer os processos fragmentários das disciplinas em geral, bem como a redução da aula a um processo burocrático e bancário. Educar é gestar o conhecimento, portanto. Menos conteúdos e situações-problema mais intensas e significativas: eis a meta desse ideal que certamente encontra muitos desafios em uma realidade escolar na qual os professores estão despreparados (e talvez até desmotivados) para rever suas próprias metodologias. Algo que, aliás, exige dedicação e tempo de reflexão, elementos raros no mundo das "empresas de educação" ou mesmo da educação orientada pelos moldes empresariais, marcados pela precarização das condições de trabalho dos docentes.

De alguma forma, a visão de competências apresentada por Perrenoud constitui-se em uma alternativa diante da crítica de Jonas: é preciso que o homo sapiens retome sua precedência sobre o homo faber, ou seja, que o homem da técnica possa recuperar seu papel reflexivo para não apenas repetir o processo de expansão tecnológica, mas também julgar as suas consequências, os custos e os danos neles contidos. Para isso, ele deve ser capaz de utilizar-se intuitivamente de vários saberes, articulá-los em situações-problema e assumir responsabilidade diante dos vários cenários possíveis do seu próprio fazer. Isso só será possível, portanto, se for recusado aquele modelo simplista de competências em nome de um modelo que se pode chamar de crítico, baseado na articulação do saber com o fazer orientado por um dever responsável. 


\section{CONSIDERAÇÕES FINAIS}

A proposta de uma ética da responsabilidade formulada por Hans Jonas evidencia o desafio de que a educação não forme apenas para o uso do poder, mas para a decisão de impor-lhe "freios voluntários" (PR, 21) em nome da garantia da preservação da vida. A sua crítica às utopias do progresso está, assim, em franca oposição ao modelo simplista de competências, na medida em que suas premissas evocam um "poder sobre o poder" (TME, 75), ou seja, a capacidade de que os sujeitos sejam capazes de articular vários saberes para medir o seu fazer. Nesse modelo, a educação deve assumir prioritariamente o debate ético em vista de qualificar os cidadãos a questionarem a própria lógica de produção a todo custo e de consumo desenfreado, cujo resultado tem sido a crise ambiental que atinge, hoje, um patamar de extrema gravidade. À educação cabe o urgente papel de preparar os indivíduos para a responsabilidade diante do futuro da vida. Para isso, deve fomentar uma "futurologia comparativa" (PR, 70), uma espécie de "futurologia da advertência" baseada na "heurística do temor" (PR, 70). Sendo capaz de prever as consequências negativas desse modelo de sociedade e dando preferência ao malum das ações presentes a fim de despertar um sentimento capaz de orientar eticamente os sujeitos de agora e evitar a catástrofe. A urgência da responsabilidade leva à educação a tarefa de enfrentar os desafios do modelo de produção exaustiva que fomenta o desgaste dos recursos naturais e a "dieta da gula" consumista, um modelo que é incentivado pelas práticas que reduziram o conhecimento ao fazer tecnicista.

Ao assumir a sua responsabilidade diante dos riscos trazidos pelo progresso tecnológico, a educação deve educar para a "modéstia nas metas, nas expectativas e no modo de vida", o que significa não incentivar uma visão de empregabilidade e sucesso profissional que está embasado na posse dos bens de consumo. Uma nova mudança é necessária: a educação deve "dar ouvidos ao pior diagnóstico e não ao melhor; porque as apostas se tornaram demasiado elevadas para arriscar", afirma Jonas (TME, 77). Educar para a "frugalidade em nossos hábitos de consumo", para a parcimônia, para a contenção, para a continência e para a temperança (TME, 77). Valores que o filósofo vai buscar na ética aristotélica não por acaso, já que elas são derivações de um modelo no qual, como se viu, o conhecimento é vizinho da virtude que une paideia e politeia, com a ressalva de que a simplicidade de agora não está mais ligada a uma busca pela perfeição pessoal, mas é "exigida com vistas à preservação de nossa morada terrena" (TME, 77). Ao invés de educar para a gula, torna-se urgente educar para a reforma dos hábitos de consumo, o que exige um questionamento da redução da ideia de felicidade à segurança financeira e ao sucesso profissional. Neste, a educação assume a ideia de competência em sentido crítico e pode ser um importante mecanismo para que a vida humana e extra-humana, como magnífica herança, seja possível no horizonte do futuro.

\section{REFERÊNCIAS}

ARISTÓTELES. Metafísica. Tradução de Vinzenzo Cocco e notas de Joaquim de Carvalho. São Paulo: Abril Cultural, 1984. (Os pensadores).

BRASIL. Ministério da Educação. Parâmetros curriculares nacionais: ensino médio. Brasília: Semtec, 1999.

FOUREZ, G. Compétences, contenus, capacites et autres cassetêtes. Forum, p. 26-31, maio 1999. Disponível em: <www. sciences.fundp.ac.be/scphilosoc/cethes/stliteracySSS.html>. Acesso em: 19 abr. 2016.

GALILEI, Galileu. O ensaiador. Tradução de Helda Barraco. 3. ed. São Paulo: Abril Cultural, 1983. (Os pensadores).

GONÇALVES, Jussemar Weiss. Paidéia e Politéia em Aristóteles. Biblos, v. 16, p. 167-175, 2007.

JONAS, Hans. O princípio responsabilidade: ensaio de uma ética para a civilização tecnológica. Tradução de Marijane Lisboa, Luiz Barros Montez. Rio de Janeiro: Contraponto: Ed. PUCRio, 2006.

JONAS, Hans. Técnica, medicina e ética. Sobre a prática do princípio responsabilidade. Tradução do Grupo de Trabalho Hans Jonas da Anpof. São Paulo: Paulus, 2013. (Ethos).

LOMBARD, Jean. Aristote: politique et education. Paris: L'Harmattan, 1994.

LYOTARD, Jean-François. O pós-moderno. Tradução de Ricardo Corrêa Barbosa. 3. ed. Rio de Janeiro: José Olympio, 1988.

PERRENOUD, Philippe et al. As competências para ensinar no século XXI: a formação dos professores e o desafio da avaliação. Porto Alegre: Artmed, 2002.

PERRENOUD, Philippe. Construir as competências desde a escola. Porto Alegre: Artes Médicas Sul, 1999.

RICARDO, Elio Carlos. Discussão acerca do ensino por competências: problemas e alternativas. Cadernos de Pesquisa, São Paulo, v. 40, n. 140, p. 605-628, ago. 2010.

YOUNG, Michael F. D. Por que o conhecimento é importante para as escolas do século XXI? Cadernos de Pesquisa, São Paulo, v. 46, n. 159, p. 18-37, 2016.

Recebido em 30-04-2016.

Aprovado em 05-01-2017. 